\title{
Propagação de Camellia sinensis: efeito do genótipo, estaca, substrato, recipiente e ácido indolbutírico
}

\author{
Juliana D Lima ${ }^{1}$; Ana Carolina B Bolfarini ${ }^{1}$; Silvia Helena M-G da Silva ${ }^{1}$; Wilson da S Moraes ${ }^{2}$ \\ ${ }^{1}$ UNESP, R. Nélson Brihi Badur 430, Vila Tupy, 11900-000 Registro-SP; judlima@registro.unesp.br; anacarolinabolfa@registro.unesp.br; \\ silvia@registro.unesp.br; ${ }^{2}$ APTA, Pólo Regional do Vale do Ribeira, Av. Wild José de Souza 454, Centro, 11900-000 Registro-SP; \\ wilson@apta.sp.gov.br
}

\section{RESUMO}

Tem sido relatado que as estacas de Camellia sinensis possuem baixa capacidade de emitir raízes, motivando assim a realização de estudos básicos para otimização do processo de propagação por estacas. Assim sendo, o presente trabalho objetivou quantificar o potencial rizogênico de diferentes genótipos e o efeito da posição da estaca no ramo e incisão na base, do substrato, tamanho do recipiente e ácido indolbutírico no enraizamento de estacas semi-lenhosas dessa espécie. Para tal, foram coletados ramos dos genótipos IAC 259, F15 e Comum, em Pariquera-Açu-SP, no inverno de 2010. Em seguida, preparadas as estacas, contendo uma gema e uma folha, foram mantidas em viveiro com $70 \%$ de sombreamento. Estacas da posição basal e mediana dos ramos são as mais adequadas para estaquia devido a menor mortalidade e maior enraizamento. A injúria na base da estaca não afeta a mortalidade e o enraizamento das estacas, porém induz à formação de calo. Também não houve diferenças na mortalidade e no enraizamento das estacas quando as mesmas foram mantidas em recipiente de 50, 90 e $120 \mathrm{~cm}^{3}$. Comparado com vermiculita, areia e casca de arroz carbonizada, o solo foi o melhor substrato para estaquia, que na presença do ferimento, juntamente com o tratamento das estacas com $10 \mathrm{~g} \mathrm{~L}^{-1}$ de AIB promoveu a maior porcentagem de enraizamento. Todavia, ainda nessa condição a mortalidade média das estacas foi de $42 \%$. O potencial de enraizamento do genótipo Comum foi superior ao do IAC 259 e F15.

Palavras-chave: Camellia sinensis, chá, estaquia, enraizamento.

\begin{abstract}
Propagation of Camellia sinensis: effect of genotype, cuttings, substrate, recipient and indolebutyric acid

It has been reported that Camellia sinensis has a low ability to emit roots, stimulating basic studies of propagation by cuttings. Therefore, this study aimed to quantify the rooting potential of different genotypes and the effect of the position of cuttings of the branch and basal injury, of the substrate, recipient size and indolebutyric acid on rooting of semi hardwood cuttings of this species. Stems were collected from three genotypes, IAC 259, F15 and Comum, grown in Pariquera-Açu, São Paulo state, Brazil, in winter 2010 and prepared cuttings, with one bud and one leaf, which were kept in a nursery with $70 \%$ of shading. The cuttings of basal and median position on branch were the most suitable due to lower mortality and greater rooting capacity. The basal injury does not affect mortality and the rooting of cuttings, but induces the formation of callus. There were also no differences in mortality and rooting of cuttings when they were kept in containers with 50, 90 and $120 \mathrm{~cm}^{3}$. The presence of incision at the base of cuttings, along with treatment with $10 \mathrm{~g} \mathrm{~L}^{-1} \mathrm{IBA}$ and soil as a substrate promoted the highest percentage of rooting. However, even in this condition the average mortality of the cuttings was $42 \%$. The rooting potential of Comum genotype was superior to the IAC 259 and F 15.
\end{abstract}

Keywords: Camellia sinensis, tea, cutting, rooting.

(Recebido para publicação em 24 de fevereiro de 2012; aceito em 26 de dezembro de 2012) (Received on February 24, 2012; accepted on December 26, 2012)

$\mathrm{O}$ chá, Camellia sinensis (família Theaceae), pode ser um arbusto ou árvore de até $16 \mathrm{~m}$ de altura (Ferrara et al., 2001). Possui folhas alternas, estipuladas, lanceoladas a obovadas, de cerca de $30 \mathrm{~cm}$ de comprimento, $2-5 \mathrm{~cm}$ de largura, pubescentes, por vezes tornando-se glabras, agudas ou acuminadas; uma a três flores em cimas axilares ou subterminais, deflexas, com $2-5 \mathrm{~cm}$ de largura, aromáticas, sépalas brancas ou rosadas, actinomorfas, 5-7 pétalas, com pedicelos de $5-15 \mathrm{~mm}$ de comprimento; estames numerosos; ovário com 3-5 carpelos, cada um com 4-6 óvulos, cápsulas deprimidas, globosas, acastanhadas, lobadas com $2 \mathrm{~cm}$ de largura, com 1-3 sementes em cada lóbulo subglobosas; aproximadamente 500 sementes $/ \mathrm{kg}$ (Ferrara et al., 2001). É utilizado como matéria prima para produção de diferentes tipos de bebidas, que são amplamente consumidas no mundo (Ruan et al., 2007). Atualmente além de serem consideradas como alimentos funcionais (Lima et al., 2009), são utilizadas como fitoterápicos, por conterem diversos compostos do metabolismo secundário com propriedades medicinais (Abeywickrama et al., 2011), tais como, polifenóis, catequinas, cafeína, teanina, saponina (Ma \& Chen, 2007).

Como conseqüência, o cultivo do chá tem grande importância econômi- ca em diversos países do mundo, tais como, Índia, Quênia, Sri Lanka, China e Japão. No Brasil, a principal região produtora do chá é o Vale do Ribeira, em São Paulo-SP, principalmente os municípios de Registro, Pariquera-Açu e Cajati (Lima et al., 2009), onde tem grande importância econômica e social. A área total ocupada pela cultura no Vale do Ribeira em 2010 foi estimada em 3.800 ha, destes $45 \%$ ocupados pelo genótipo IAC $259,29 \%$ por F15 e $18 \%$ por Comum.

A propagação desta espécie vegetal no Vale do Ribeira é realizada por meio da estaquia, utilizando material semi-lenhoso com única folha (Lima et 
al., 2011). No entanto, este método de propagação apresenta problemas, tais como dificuldade de enraizamento na ausência do pré-tratamento das estacas com auxina (Sharma et al., 1999; Rout, 2006), alta taxa de mortalidade (Lima et al., 2011; Rout, 2006), enraizamento dependente de época do ano propícia (Mondal \& Chand, 2002; Lima et al., 2011), além de longo tempo para formação dos primórdios radiculares (Mondal et al., 2004).

Alguns trabalhos na literatura apontam que estacas coletadas em diferentes posições no ramo possuem diferentes capacidades de emitir raízes (Pio et al., 2006) e que a aplicação nas estacas de soluções contendo ácido indolbutírico tem permitido aumentos significativos na emissão de raízes (Pio et al., 2005). Outro importante fator para a adequada emissão de raízes é o substrato (Ehlert et al., 2004), que além de sustentar a estaca, deve proporcionar ambiente adequado para o enraizamento (Bastos et al., 2007). O recipiente deve acondicionar volume adequado de substrato e permitir boa aeração e drenagem, além de permitir o crescimento e boa conformação das raízes (Tofanelli et al., 2003).

O objetivo do presente trabalho foi quantificar o potencial rizogênico de diferentes genótipos e o efeito da posição da estaca no ramo e incisão na base, do substrato, tamanho do recipiente e ácido indolbutírico no enraizamento de estacas semi-lenhosas de Camellia sinensis.

\section{MATERIAL E MÉTODOS}

No inverno de 2010, foram coletados ramos semi-lenhosos de matrizes de três genótipos de Camellia sinensis cultivados no Vale do Ribeira, sendo eles: IAC 259, F15 e Comum. Os dois primeiros são híbridos da variedade assamica (chá de Assam) e o último, híbrido da variedade sinensis (chá da China). A coleta foi realizada em plantas-matriz de cerca de 12 anos de idade, da empresa Yamatea localizada em Pariquera-Açu -SP (2442'51''S, 4252'58'O, altitude $25 \mathrm{~m}$ ). De acordo com a classificação de Köppen, o clima da região é tropical úmido, sem estação seca definida (Af). Em seguida, o material vegetal foi le- vado para o Campus Experimental de Registro, onde foram preparadas estacas de 5 a $8 \mathrm{~cm}$ de comprimento e cerca de 0,5 a $0,7 \mathrm{~cm}$ de diâmetro, contendo uma folha e uma gema, que foram utilizadas nos experimentos.

No primeiro experimento determinou-se o efeito da posição de coleta das estacas sobre a sobrevivência e enraizamento. O recipiente utilizado foi tubete de polipropileno de seção circular com diâmetro interno de $3,5 \mathrm{~cm}, 14,0 \mathrm{~cm}$ de altura e capacidade total de $90 \mathrm{~cm}^{3}$, preenchido com vermiculita lavada com granulometria média. O delineamento experimental utilizado foi inteiramente casualizado, em esquema fatorial $3 \mathrm{x}$ 3 , sendo os tratamentos constituídos de três genótipos (IAC 259, F15 e Comum) e três tipos de estacas (porção apical, mediana e basal do ramo), com quatro repetições de oito estacas cada tratamento.

No segundo experimento, determinou-se o efeito da incisão na base da estaca no enraizamento. $\mathrm{O}$ delineamento experimental foi inteiramente casualizado em fatorial $3 \times 2$, sendo os tratamentos constituídos dos três genótipos e dois tipos de incisão (presença e ausência de incisão), com quatro repetições de oito estacas cada tratamento. A incisão foi realizada por meio de dois cortes laterais, a partir da base de estacas, de cerca de 1,0 cm de comprimento, sendo removido o tecido de revestimento entre os dois cortes. Utilizaram-se estacas da porção basal e mediana do ramo, vermiculita lavada com granulometria média como substrato e tubete como recipiente, com as mesmas dimensões do utilizado no primeiro experimento $\left(90 \mathrm{~cm}^{3}\right)$.

No terceiro experimento determinou-se o efeito do tipo de recipiente no desenvolvimento das estacas. O delineamento experimental utilizado foi inteiramente casualizado, em esquema fatorial $3 \times 3$, sendo três genótipos e tubetes de polipropileno de seção circular com capacidade de 50, 90 e $120 \mathrm{~cm}^{3}$, com quatro repetições de oito estacas cada tratamento. $\mathrm{O}$ diâmetro interno e altura dos recipientes utilizados foram, respectivamente, de 2,9 e $12,0 \mathrm{~cm}$ para tubete de $50 \mathrm{~cm}^{3}$, de 3,5 e $14,0 \mathrm{~cm}$ para tubete de $90 \mathrm{~cm}^{3}$ e de 3,8 e $14,5 \mathrm{~cm}$ para tubete de $120 \mathrm{~cm}^{3}$. Utilizaram-se estacas da porção basal e mediana do ramo, vermiculita lavada com granulometria média como substrato.

No quarto experimento determinou-se o efeito de diferentes substratos na estaquia. Para tal, foram obtidas estacas da porção basal e mediana do ramo, que foram mantidas em tubete com as mesmas dimensões do utilizado no primeiro experimento $\left(90 \mathrm{~cm}^{3}\right)$. $\mathrm{O}$ delineamento experimental foi inteiramente casualizado, em esquema fatorial $3 \times 4$, sendo três genótipos e quatro substratos (areia, casca de arroz carbonizada, solo e vermiculita com granulometria média), com oito repetições de oito estacas cada tratamento. $\mathrm{O}$ pH em água determinado após 30 minutos de agitação da mistura substrato:água na proporção $1: 5(\mathrm{v} / \mathrm{v})$ foi de 6,$7 ; 6,8 ; 4,2$ e 6,5, respectivamente, para areia, casca de arroz carbonizada, solo e vermiculita. A análise química do solo utilizado apresentou $\mathrm{pH}$ em $\mathrm{CaCl}_{2}$, 4,8; matéria orgânica, $25 \mathrm{~g} \mathrm{dm}^{-3}$; P, $6 \mathrm{mg}$ $\mathrm{dm}^{-3}$; K 0,16 $\mathrm{cmol}_{\mathrm{c}} \mathrm{dm}^{-3}$; $\mathrm{Ca}, 2,4 \mathrm{cmol}_{\mathrm{c}}$ $\mathrm{dm}^{-3} ; \mathrm{Mg}, 1,3 \mathrm{cmol}_{\mathrm{c}} \mathrm{dm}^{-3} ; \mathrm{S}_{-} \mathrm{SO}_{4}^{-}, 7,4$ $\mathrm{mg} \mathrm{dm}{ }^{-3} ; \mathrm{H}+\mathrm{Al}, 4,5 \mathrm{cmol}_{\mathrm{c}} \mathrm{dm}^{-3} ; \mathrm{Al}, 0,3$ $\mathrm{cmol}_{\mathrm{c}} \mathrm{dm}^{-3}$; B, 0,4 $\mathrm{mg} \mathrm{dm}^{-3}$; Cu, 0,7 mg $\mathrm{dm}^{-3} ; \mathrm{Fe}, 815 \mathrm{mg} \mathrm{dm}^{-3} ; \mathrm{Mn}, 1,7 \mathrm{mg}$ $\mathrm{dm}^{-3} ; \mathrm{Zn}, 5,4 \mathrm{mg} \mathrm{dm}^{-3}$. A análise física do solo revelou $51 \%$ de areia, $26 \%$ de silte e $23 \%$ de argila.

No quinto experimento estudou-se o efeito da auxina ácido indolbutírico (AIB) no enraizamento de estacas basais e medianas do ramo utilizando como recipiente tubetes com $90 \mathrm{~cm}^{3}$, das mesmas dimensões do utilizado no primeiro experimento e substrato solo, cuja análise química revelou $\mathrm{pH}$ em $\mathrm{CaCl}_{2}, 4,1$, matéria orgânica, $25 \mathrm{~g} \mathrm{dm}^{-3}$; P, $4 \mathrm{mg} \mathrm{dm}^{-3}$; K, 0,10 $\mathrm{cmol}_{\mathrm{c}} \mathrm{dm}^{-3}$; Ca, 2,1 $\mathrm{cmol}_{\mathrm{c}} \mathrm{dm}^{-3} ; \mathrm{Mg}, 0,9 \mathrm{cmol}_{\mathrm{c}} \mathrm{dm}^{-3} ; \mathrm{S}_{-} \mathrm{SO}_{4}^{-}$, $4,3 \mathrm{mg} \mathrm{dm}^{-3} ; \mathrm{H}+\mathrm{Al}, 5,2 \mathrm{cmol} \mathrm{dm}^{-3} ; \mathrm{Al}$, $0,4 \mathrm{cmol} \mathrm{dm}^{-3}$; B, 0,3 $\mathrm{mg} \mathrm{dm}^{-3} ; \mathrm{Cu}, 0,5$ mg dm${ }^{-3}$; Fe, $919 \mathrm{mg} \mathrm{dm}^{-3}$; Mn, 1,4 mg $\mathrm{dm}^{-3} ; \mathrm{Zn}, 4,9 \mathrm{mg} \mathrm{dm}^{-3}$. O pH em água foi de 3,6 e a análise física indicou a presença de $53 \%$ de areia, $31 \%$ de silte e $16 \%$ de argila. Após a obtenção das estacas, foram feitos dois cortes laterais, a partir da base, de cerca de 1,0 cm de comprimento e, na sequência, a imersão em solução de ácido indolbutírico (AIB) contendo 0, 2, 4, 6, 8 e $10 \mathrm{~g} \mathrm{~L}^{-1}$ durante 30 segundos. $\mathrm{O}$ delineamento experimental utilizado foi inteiramente 
casualizado em esquema fatorial $3 \times 6$, sendo três genótipos e seis concentrações de AIB, com quatro repetições de oito estacas cada tratamento.

Em todos os experimentos realizados, o ambiente de enraizamento foi viveiro de $57,6 \mathrm{~m}^{2}(6,4 \mathrm{~m}$ de largura e 9,0 $\mathrm{m}$ de comprimento) e pé direito de 4,0 m, coberto com tela preta com $70 \%$ de sombreamento. As irrigações foram realizadas quatro vezes por dia por meio de microaspersores.

As avaliações foram realizadas aos 60 dias após o início dos experimentos e incluíram a determinação da mortalidade e a porcentagem de estacas vivas enraizadas, com calo e brotações. Nas estacas enraizadas também foram determinados o número e o tamanho das raízes formadas.

A análise estatística foi realizada no programa estatístico Sisvar, versão 4.2 (Ferreira, 2011). Inicialmente, os dados coletados foram submetidos aos testes de normalidade (teste de Lilliefors) e homogeneidade (teste de Cochran), que evidenciaram ser necessária a realização de transformação dos dados, optando-se pelo emprego da raiz quadrada $(\mathrm{x}+1)^{0,5}$ ou raiz quarta $(\mathrm{x}+1)^{0,25}$ para adequar os dados à pressuposição da homogeneidade das variâncias residuais (Couto et al., 2009). Posteriormente, foi realizada a análise da variância por meio do teste $\mathrm{F}$, seguida da comparação das médias pelo teste de Tukey ou análise da regressão, sendo a escolha da equação baseada na significância do coeficiente de determinação por meio do teste $t$.

\section{RESULTADOS E DISCUSSÃO}

\section{Experimento 1}

A posição no ramo influenciou a mortalidade da estaca. Independente do genótipo, as maiores mortalidades ocorreram em estacas da porção apical (Tabela 1). A mortalidade das estacas também diferiu entre os genótipos estudados, sendo mais baixa no genótipo Comum, em relação aos demais.

A posição da estaca no ramo afetou o enraizamento. Estacas basais e medianas apresentaram maior porcentagem de enraizamento quando comparadas com estacas apicais nos três genótipos.
(Tabela 1). Na literatura há grande variação na resposta do enraizamento à posição da estaca do ramo. Em Platanus acerifolia (Vlachov, 1988), estacas obtidas da porção basal do ramo apresentaram maior capacidade de enraizamento, enquanto em Pfaffia glomerata, estacas da porção mediana e basal apresentaram maior desempe- nho (Nicoloso et al., 1999). Quanto à influência do genótipo, Comum, seguido do IAC 259 e por último, do F15 apresentaram em ordem decrescente as maiores porcentagens de enraizamento em estacas basais e medianas.

A formação de calo foi afetada apenas pelos efeitos isolados do genótipo e posição da estaca no ramo. Os valores

Tabela 1. Mortalidade e enraizamento nas estacas vivas de Camellia sinensis em função do genótipo e da posição no ramo (mortality and rooting in living cuttings of Camellia sinensis depending on genotype and position on branch). Registro, UNESP, 2010.

\begin{tabular}{lccc}
\hline & Comum & IAC 259 & F15 \\
\cline { 2 - 4 } & \multicolumn{3}{c}{ Mortalidade (\%) } \\
\hline Basal & $50,00 \mathrm{C} \mathrm{b}$ & $71,88 \mathrm{~B} \mathrm{a}$ & $75,00 \mathrm{C} \mathrm{a}$ \\
Mediana & $65,63 \mathrm{~B} \mathrm{~b}$ & $87,50 \mathrm{~B} \mathrm{a}$ & $87,50 \mathrm{~B} \mathrm{a}$ \\
Apical & $96,88 \mathrm{~A} \mathrm{a}$ & $100,00 \mathrm{~A} \mathrm{a}$ & $100,00 \mathrm{~A} \mathrm{a}$ \\
\hline \multicolumn{4}{c}{ Enraizamento nas estacas vivas (\%) } \\
\hline Basal & $25,58 \mathrm{~A} \mathrm{a}$ & $13,58 \mathrm{~A} \mathrm{~b}$ & $7,85 \mathrm{~A} \mathrm{c}$ \\
Mediana & $23,12 \mathrm{~A} \mathrm{a}$ & $13,11 \mathrm{~A} \mathrm{~b}$ & $5,61 \mathrm{~A} \mathrm{c}$ \\
Apical & $2,69 \mathrm{~B} \mathrm{a}$ & $0,00 \mathrm{~B} \mathrm{a}$ & $0,00 \mathrm{~B} \mathrm{a}$ \\
\hline
\end{tabular}

Médias seguidas da mesma letra maiúscula na coluna e da mesma letra minúscula na linha não diferem entre si pelo teste de Tukey, $p>0,05$ (means followed by the same uppercase letters in the columns and lowercase letters in the lines do not differ from each other by the Tukey test, $\mathrm{p}>0.05$ ).

Tabela 2. Porcentagem de estacas vivas de Camellia sinensis com calo e raiz e número médio de raízes formadas nas estacas mantidas em areia, casca de arroz carbonizada (CAC), solo e vermiculita (Verm) (percentage of Camellia sinensis cutting with callus and root and average number of roots in the cuttings maintained in sand, carbonized rice hull (CAC), soil and vermiculite (Verm)). Registro, UNESP, 2010.

\begin{tabular}{lccc}
\hline & Comum & IAC 259 & F15 \\
\cline { 2 - 4 } & \multicolumn{3}{c}{ Estacas vivas com calo (\%) } \\
\hline Areia & $24,10 \mathrm{~B} \mathrm{a}$ & $25,00 \mathrm{~B} \mathrm{a}$ & $20,18 \mathrm{~B} \mathrm{a}$ \\
CAC & $23,25 \mathrm{~B} \mathrm{a}$ & $24,42 \mathrm{~B} \mathrm{a}$ & $15,25 \mathrm{C} \mathrm{b}$ \\
Solo & $52,75 \mathrm{~A} \mathrm{a}$ & $54,25 \mathrm{~A} \mathrm{a}$ & $34,75 \mathrm{~A} \mathrm{~b}$ \\
Verm & $27,19 \mathrm{~B} \mathrm{a}$ & $26,75 \mathrm{~B} \mathrm{a}$ & $14,24 \mathrm{C} \mathrm{b}$ \\
\hline \multicolumn{5}{c}{ Estacas vivas com raiz (\%) } \\
\hline Areia & $25,00 \mathrm{~B} \mathrm{a}$ & $22,50 \mathrm{~B}$ a & $23,25 \mathrm{~B} \mathrm{a}$ \\
CAC & $24,50 \mathrm{~B} \mathrm{a}$ & $23,75 \mathrm{~B} \mathrm{a}$ & $21,99 \mathrm{~B} \mathrm{a}$ \\
Solo & $54,03 \mathrm{~A} \mathrm{a}$ & $33,75 \mathrm{~A} \mathrm{~b}$ & $35,07 \mathrm{~A} \mathrm{~b}$ \\
Verm & $28,63 \mathrm{~B} \mathrm{a}$ & $22,51 \mathrm{~B} \mathrm{a}$ & $25,75 \mathrm{~B} \mathrm{a}$ \\
\hline \multicolumn{4}{c}{ Número médio de raízes formadas } \\
\hline Areia & $2,73 \mathrm{BC} \mathrm{b}$ & $3,15 \mathrm{~B} \mathrm{~b}$ & $4,91 \mathrm{~B} \mathrm{a}$ \\
CAC & $3,12 \mathrm{~B} \mathrm{~b}$ & $3,04 \mathrm{~B} \mathrm{~b}$ & $4,10 \mathrm{C} \mathrm{a}$ \\
Solo & $5,65 \mathrm{~A} \mathrm{c}$ & $6,52 \mathrm{~A} \mathrm{~b}$ & $7,23 \mathrm{~A} \mathrm{a}$ \\
Verm & $2,47 \mathrm{C} \mathrm{b}$ & $2,53 \mathrm{~B} \mathrm{~b}$ & $4,54 \mathrm{BC} \mathrm{a}$ \\
\hline
\end{tabular}

Médias seguidas da mesma letra maiúscula na coluna e da mesma letra minúscula na linha não diferem entre si pelo teste de Tukey, $\mathrm{p}>0,05$ (means followed by the same uppercase letters in the columns and lowercase letters in the lines do not differ from each other by the Tukey test, $\mathrm{p}>0.05$ ). 
médios de porcentagem de estaca com calo foram de 12,$05 ; 11,61$ e 5,60\%, respectivamente, para o genótipo Comum, IAC 259 e F15, não havendo diferenças entre Comum e IAC 259, que apresentaram porcentagem superior a F15 ( $\mathrm{p} \leq 0,05)$. Em relação à posição dos ramos, a formação de calo ocorreu somente nas estacas vivas provenientes da porção basal $(17,18 \%)$ e mediana do ramo $(12,08 \%)$, sendo a diferença entre as duas posições significativa $(\mathrm{p} \leq 0,05)$. Yuerong et al. (1985) e Koyuncu \& Balta (2004) observaram que em estacas de chá a formação de raiz adventícia pode ser iniciada após a formação do calo; no entanto, em estacas com calos que crescem muito, frequentemente não ocorre emissão de raiz (Koyuncu \& Balta, 2004).

Em relação à porcentagem de brotações nas estacas vivas, apenas os efeitos isolados do genótipo e posição da estaca no ramo foram significativos para essa variável. A maior porcentagem de estacas com brotações ocorreu no genótipo Comum (20,78\%) e IAC 259 (19,88\%), que não diferiram entre si, e foram superiores ao $\operatorname{F} 15(2,75 \%)(\mathrm{p} \leq 0,05)$. Independente do genótipo, também não houve diferenças na porcentagem de estacas basais $(22,16 \%)$ e medianas $(21,25 \%)$ quanto à presença de brotação $(\mathrm{p} \leq 0,05)$.

\section{Experimento 2}

A presença do corte na base da estaca não influenciou a mortalidade das estacas, bem como, a porcentagem de estacas vivas com raiz e brotação. No entanto, houve aumento significativo na porcentagem de estacas com calo, que foi em média $50,18 \%$ e de apenas de $16,54 \%$ na ausência do ferimento $(\mathrm{p} \leq 0,05)$, independente do genótipo. $\mathrm{O}$ ferimento da base da estaca é benéfico para o enraizamento de diversas espécies lenhosas, por estimular a divisão celular e a formação de calo (Biasi et al., 2000). Além do estímulo à divisão celular, supõe-se que o ferimento na base da estaca de chá pode promover a liberação de fenóis, que são considerados elementos-chave na indução da formação de raízes adventícias no chá (De Klerk et al., 1999; Rout, 2006). Em Prunus persica (Tofanelli et al., 2005), a remoção da casca do ferimento na base da estaca promoveu o enraizamento, igualmente em figueira (Pauletti et al., 2010), enquanto em estacas de Averrhoa carambola não houve efeito (Bastos et al., 2009).

\section{Experimento 3}

Observou-se, que os recipientes com diferentes tamanhos não afetaram nenhuma variável analisada, apenas houve efeito isolado do genótipo, o que pode ser atribuído ao reduzido número e tamanho das raízes formadas nas estacas e a grande disponibilidade de área nos recipientes utilizados para o crescimento das raízes em número e profundidade. Quanto ao tamanho, estacas do genótipo Comum se destacaram apresentando comprimento médio das raízes de 2,98 $\mathrm{cm}$, que foi superior ao comprimento apresentado por IAC $259(1,93 \mathrm{~cm})$ e F15 1,25 cm $(\mathrm{p} \leq 0,05)$. O número médio de raízes formadas nas estacas do genótipo Comum $(2,78)$ e IAC 259 $(2,81)$ não diferiram entre si, e foram inferiores ao número formado em F15 $(5,03)(\mathrm{p} \leq 0,05)$.

\section{Experimento 4}

A mortalidade das estacas foi afetada apenas pelos efeitos isolados do substrato e genótipo, enquanto a porcentagem de estacas vivas com calo e raiz e o número médio de raízes formadas foram afetados pela interação entre substrato e genótipo. Houve diferenças na mortalidade das estacas mantidas nos diferentes substratos, sendo mais baixa no solo $(50,00 \%)$, areia $(56,25 \%)$ e vermiculita $(56,25 \%)$, que não diferiram entre si, em relação à casca de arroz carbonizada $(87,50 \%)(p \leq 0,05)$. Quanto ao efeito do genótipo, mais baixa no Comum (53,13\%), seguido do IAC $259(62,50 \%)$ e por último do F15 (71,88\%), sendo as

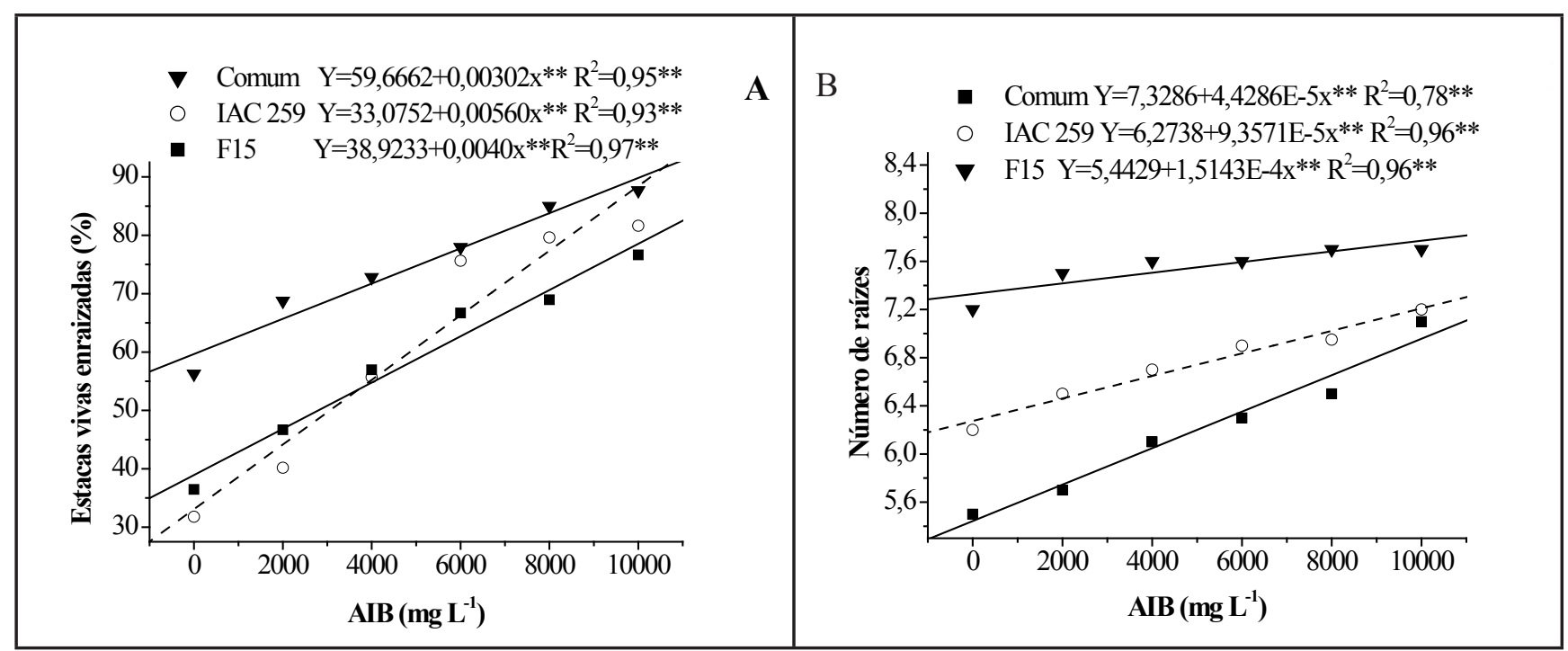

Figura 1. Porcentagem de enraizamento (A) e número de raízes (B) formadas em estacas de Camellia sinensis coletadas no inverno, com ferimento na base, tratadas com AIB e mantidas em solo (rooting percentage (A) and root number (B) formed in cuttings of Camellia sinensis collected in winter, with injury at the base, treated with IBA and kept in soil). Registro, UNESP, 2010.

${ }^{*} \mathrm{p} \geq 0,01 ; \mathrm{R}^{2}=$ coeficiente de determinação da regressão $\left(\mathrm{p} \geq 0,01 ; \mathrm{R}^{2}=\right.$ regression coefficient of determination). 
diferenças significativas apenas quando se comparou Comum e F15 ( $\mathrm{p} \leq 0,05)$.

A porcentagem de estacas vivas com calo e enraizadas independente do genótipo foi superior no substrato solo, quando comparado aos demais (Tabela 2). O substrato é um dos fatores de maior importância para o enraizamento de estacas, pois além de servir de suporte para a sustentação da estaca, deve reter a água fornecida via irrigação por um longo período de tempo e fornecer ambiente escuro e aeração para a base da estaca (Bastos et al., 2007). A porcentagem de estacas dos genótipos Comum e IAC 259 com calo foi superior comparado com F15, quando as mesmas foram mantidas na casca de arroz carbonizada, solo e vermiculita, diferença que não foi observada quando as estacas foram mantidas em areia (Tabela 2). Apenas quando o substrato utilizado foi solo houve diferenças no potencial rizogênico dos genótipos, tendo Comum se destacado em relação a IAC 259 e F15, que não diferiram entre si (Tabela 2).

O maior número de raízes observado em estacas mantidas em solo pode estar relacionado com o $\mathrm{pH}$ mais baixo desse substrato (Tabela 2). Segundo Nakamura et al. (2001), o pH do substrato para estaquia de chá deve ser baixo e quando alto induz a formação de calo (Hamid et al., 2006). Em geral, o maior número de raízes foi observado em F15, seguido de IAC 259, e por último, do Comum (Tabela 2). Os substratos não promoveram diferenças no tamanho das raízes, também não foram observadas diferenças genotípicas significativas para essa variável. A formação de brotações nas estacas não foi influenciada pelo tipo de substrato utilizado.

\section{Experimento 5}

A resposta do enraizamento à aplicação de AIB, na presença de ferimento, em estacas mantidas em solo foi linear para os três genótipos, indicando que a concentração ótima de AIB não foi atingida (Figura 1A). Em concentrações inferiores a $8 \mathrm{~g} \mathrm{~L}^{-1}$ a porcentagem de estacas enraizadas do genótipo Comum foi superior às estacas de IAC 259 e F15, demonstrando que esse genótipo teve maior capacidade de enraizamento em concentrações mais baixas de auxina.
No entanto, a $10 \mathrm{~g} \mathrm{~L}^{-1}$ não houve diferenças entre os genótipos. O número de raízes formadas nas estacas aumentou proporcionalmente com o aumento da concentração de AIB na solução de tratamento (Figura 1B), sendo mais elevado no genótipo F15, seguido do IAC 259, e por último do Comum. No entanto, não houve efeito da concentração de AIB e do genótipo no tamanho das raízes formadas, que apresentaram em média 2,14 cm de comprimento.

Em outros estudos, também foi observado que o tratamento com AIB estimula a formação de raízes adventícias em estacas de chá (Banerjee \& Agarwal, 1990; Sharma et al., 1999; Gunasekare \& Evans, 2000; Rout, 2006), que em termos bioquímicos, é induzida pelo aumento da atividade de peroxidades e conteúdo de fenóis (Rout, 2006).

A mortalidade das estacas, na presença do ferimento e tratamento com AIB, foi influenciada apenas pelo genótipo, ocorrendo em média em $40,63 \%$ das estacas. Comparado com experimentos anteriores, a mortalidade das estacas manteve-se alta, mesmo havendo maior porcentagem de enraizamento, indicando que provavelmente a mortalidade não esteja relacionada com a dificuldade de enraizamento e sim com o ambiente de enraizamento. A formação de calo foi influenciada pelo genótipo, porém foi independente da concentração de AIB, ocorrendo em cerca de $11,13 \%$ das estacas de Comum, $9,37 \%$ das estacas de IAC 259 e 19,45\% das estacas de F15, não havendo diferenças entre os dois primeiros, que foram superiores ao último genótipo $(\mathrm{p} \leq 0,05)$. A porcentagem de estacas com brotação não foi influenciada pelo genótipo e concentração de AIB e ocorreu em média em $89,63 \%$ das estacas. Todas as estacas com raiz apresentaram brotações.

Dall'Orto (2011) obteve enraizamento médio de estacas herbáceas e lenhosas do genótipo IAC 259 de até $65,0 \%$ após aplicação de AIB em baixa concentração $\left(0,30,60\right.$ e $\left.90 \mathrm{mg} \mathrm{L}^{-1}\right)$ por imersão lenta (24 horas), utilizando vermiculita como substrato e casa-de-vegetação com sistema de irrigação por nebulização como ambiente de enraizamento. No presente estudo, para a mesma cultivar usando o solo como substrato e estacas semilenhosas tratadas com AIB de 6 a $10 \mathrm{~g} \mathrm{~L}^{-1}$ por imersão rápida, obteve-se porcentagens de enraizamento mais elevadas do que as obtidas por Dall'Orto (2011) (Figura 1).

Conclui-se que, em viveiro, estacas de Camellia sinensis da porção basal e mediana do ramo, com incisão na base, tratadas com $10 \mathrm{~g} \mathrm{~L}^{-1}$ de AIB e mantidas em solo com $\mathrm{pH}$ baixo apresentam as maiores porcentagens de enraizamento, com diferenças no potencial rizogênico dos genótipos, com superioridade do Comum em relação a IAC 259 e F15.

\section{AGRADECIMENTOS}

À FUNDUNESP e FAPESP, pelo auxílio financeiro e ao $\mathrm{CNPq}$, pela bolsa de iniciação científica concedida à primeira co-autora.

\section{REFERÊNCIAS}

ABEYWICKRAMA KRW; RATNASOORIYA WD; AMARAKOON AMT. 2011. Oral hypoglycaemic, antihyperglycaemic and antidiabetic activities of Sri Lankan Broken Orange Pekoe Fannings (BOPF) grade black tea (Camellia sinensis L.) in rats. Journal of Ethnopharmacology 135: 278-286.

BANERJEE M; AGARWAL B. 1990. In vitro rooting tea, Camellia sinensis (L.) O. Kuntze. Indian Journal Experimental Biology 28: 936-939.

BASTOS DC; PIO R; SCARPARE FILHO JA; LIBARDI NM; ALMEIDA LFP; ENTELMANN FA 2007. Diferentes substratos na produção de porta-enxertos de caramboleira. Ciência e Agrotecnologia 31: 312-316.

BASTOS DC; SCARPARE FILHO JA; LIBARDI NM; PIO R. 2009. Estiolamento, incisão na base da estaca e uso do ácido indolbutírico na propagação da caramboleira por estacas lenhosas. Ciência e Agrotecnologia 33: 313-318.

BIASI LA; STOLTE RE; SILVA MF. 2000. Estaquia de ramos semilenhosos de pessegueiro e nectarina. Revista Brasileira de Fruticultura 22: 421-425.

COUTO MRM; LÚCIO AD; LOPES SJ; CARPES RH. 2009. Transformações de dados em experimentos com abobrinha italiana em ambiente protegido. Ciência Rural 39: 17011707.

DALL'ORTO LTC. 2011. Auxinas e tipo de estacas no enraizamento de Camellia sinensis. Piracicaba: USP-ESALQ. 75p (Tese mestrado).

DE KLERK GJ; KRIEKEN WVD; JONG JC. 1999. The formation of adventitious roots: new concepts, new possibilities. In Vitro Cell Development Biology-Plant 35: 189-199.

EHLERT PAD; LUZ JMQ.; INNECCO R. 2004. Propagação vegetativa da alfavaca- 
cravo utilizando diferentes tipos de estacas e substratos. Horticultura Brasileira 22: 10-13.

FERRARA L; MONTESANO D; SENATORE A. 2001. The distribution of minerals and flavonoids in the tea plant (Camellia sinensis). II Farmaco 56: 397-401.

FERREIRADF. 2011. Sisvar: a computer statistical analysis system. Ciência e Agrotecnologia 35: 1039-1042.

GUNASEKARE MTK; EVANS PK. 2000. In vitro rooting of microshoots of tea (Camellia sinensis L.). SriLanka Journal Tea Science 66: 5-15.

HAMID FS; AHMAD T; KHAN BM; WAHEED A; AHMED N. 2006. Effect of soil pH in rooting and growth of tea cuttings (Camellia sinensis 1.) at nursery level. Pakistan Journal of Botany 38: 293-300.

KOYUNCU F; BALTA F. 2004. Adventitious root formation in leaf-bud cuttings of tea (Camellia sinensis L.). Pakistan Journal of Botany 36: 763-768.

LIMA JD; MAZZAFERA P; MORAES WS; SILVA RB. 2009. Chá: aspectos relacionados à qualidade e perspectivas. Ciência Rural 39: 1270-1278.

LIMA JD; LIMA APS; BOLFARINI ACB; MODENESE-GORLA DA SILVA SH 2011. Enraizamento de estacas de Camellia sinensis L. em função da época de coleta de ramos, genótipos e ácido indolbutírico. Ciência Rural 41: $230-235$.

MA C; CHEN L. 2007. Research progress on isolation and cloning of functional genes in tea plants. Frontiers of Agriculture in China
1: 449-455.

MONDAL TK; CHAND PK. 2002. Detection of genetic instability among the miocropropagated tea (Camellia sinensis) plants. In Vitro Cellular and Developmental Biology-Plant 37: 1-5.

MONDAL TK; BHATTACHARYA A; LAXMIKUMARAN M; ARUJA PS 2004. Recent advances of tea (Camellia sinensis) biotechnology. Plant Cell, Tissue and Organ Culture 76: 195-254.

NAKAMURA Y; TAKANO H; MORITAA 2001. Effects of pot size, soil type, and sodium alginate application on the soil prevention rate at the transplanting of tea cuttings grown in paper pots. Japanese Journal of Crop Science 70: 28-33.

NICOLOSO FT; FORTUNATO RP; FOGAÇA MAF. 1999. Influência da posição da estaca no ramo sobre o enraizamento de Pfaffia glomerata (Spreng.) Pedersen em dois substratos. Ciência Rural 29: 277-283.

PAULETTI DR; PIO R; BARBOSA W; CHAGAS EA; KOTZ TE 2010. Enraizamento de segmentos nodais caulinares de figueira. Bragantia 69: 877-882.

PIOR; RAMOS JD; CCHALFUNNNJ; GONTIJO TCA; MENDONÇA V; CARRIJO EP; CHAGAS EA. 2006. Propagação de estacas apicais de figueira: diferentes ambientes, ácido indolbutiríco e tipo de estaca. Ciência e Agrotecnologia 30: 1021-1026.

PIO R; BASTOS DC; BERTI AJ; SCARPARE FILHO JA; MOURÃO FILHO FAA; ENTELMANN FA; ALVES ASR; BETTIOL NETO JE. 2005. Enraizamento de diferentes tipos de estacas de oliveira (Olea europaea L.) utilizando-se ácido indolbutírico. Ciência e Agrotecnologia 29: 562-567.

ROUT GR. 2006. Effect of auxins on adventitious root development from single node cuttings of Camellia sinensis (L.) Kuntze and associated biochemical changes. Plant Growth Regulation 48: 111-117.

RUAN J; GERENDÁS J; HÄRDTER R; SATTELMACHER B. 2007. Effect of root zone $\mathrm{pH}$ and form and concentration of nitrogen on accumulation of quality-related components in green tea. Journal of the Science of Food and Agriculture 87: 15051516.

SHARMA M; SOOD A; NAGAR PK; PRAKASH O. 1999. Direct rooting and hardening of tea microshoots in the field. Plant Cell, Tissue and Organ Culture. 58: 111-118.

TOFANELLI MBD; RODRIGUES JD; ONO EO. 2003. Enraizamento de estacas lenhosas de pessegueiro cv. Okinawa em diferentes diâmetros de ramos, substratos e recipientes. Ciência Rural 33: 437-442

TOFANELLI MBD; RODRIGUES JD; ONO EO. 2005. 2,6-Di-hidroxiacetofenona e tipo de corte basal no enraizamento de estacas semilenhosas de pessegueiro 'Okinawa'. Ciência Rural 35: 462-464.

VLACHOV DD. 1988. Vegetative propagation of Platanus sp. L. through rooting of cuttings. Acta Horticulture 226: 375-378.

YUERONG L; ZUSHENG L; WANFANG Z. 1985. Anatomic and biochemical studies during rooting in tea cutting. Journal of Tea Science 1: 48-53. 